\title{
EFICIÊNCIA DO NICOSULFURON NO CONTROLE DE CAPIM-MASSAMBARA NA CULTURA DO MILHO
}

\author{
JOEL I. FAHL ${ }^{2}$ e MARIA LUIZA C. CARELLI ${ }^{2}$
}

\begin{abstract}
Um experimento de campo foi conduzido em Rio Claro, SP, em 1991/92 para estudar a eficiência do nicosulfuron no controle do capimmass ambará (Sorghum halepen se), co mo infestante da cultura do milho. O nicosulfuron foi aplicado em pós-emergência inicial, quando o capim-massambará estava com 3 a 5 folhas, nas doses de 40, 50, 60, e $80 \mathrm{~g} / \mathrm{ha}$, e em pósemergência tardia (capimmassambará com 4 a 6 folhas), nas doses de 50, 60 e $80 \mathrm{~g} / \mathrm{ha}$. Foram ac re scentados tratamen tos com atrazine + simazine $(1500+1500 \mathrm{~g} / \mathrm{ha})$, com e sem a adição de óleo mineral, nas mesmas épocas de aplicação do nicosulfuron. Verificou-se que o nicosulfuron apresent ou excelente controle do capimmassambará, atingindo $100 \%$ de controle aos 50
\end{abstract}

RESUMO

dias após a aplicação, independente das doses e épocas de aplicação. As aplicações de atrazine + simazine não mostraram controle satisfatório do capim massambará em pós-emergência, principalmente quando efetuadas tardias e com adição de óleo mineral. O controle do capimmassambará com nicosulfuron em pós-emergência inicial e tardia aumentou a produção de milho, respectivamente em 44 e $34 \%$, em relação à testemunha não capinada. Não foi observado qualquer sinal de fitotoxicidade nas plantas de milho, em todos os tratamentos efetuados

Palavras chave: Sorghum halepense, sulfoniluréia, controle pós-emergência, época de aplicação, triazinas.

\section{ABSTRACT}

\section{Nicosulfuron efficacy on johnsongrass control in field corn}

A field experiment was conducted at Rio Claro, SP, Brazil, during 1991/92 to evaluate the efficacy of nicosulfuron for postemergence control of johnsongrass (Sorghum halepense) in field com grown under conventional conditions. Nicosulfuron was applied on early postemergence, on johnsongrass with 2 to 5 leaves, at rates of 40 , 50,60 e $80 \mathrm{~g} / \mathrm{ha}$, and late postemergence (4 to 6 leaves ) at rates of 50,60 and $80 \mathrm{~g} / \mathrm{ha}$. Two additional treatments of atrazine + simazine (1500 $+1500 \mathrm{~g} / \mathrm{ha}$ ), with and without mineral oil, were applied at the same time of nicosulfuron. Treatments of nicosulfuron showed an exellent control of johnsongrass, irrespectively of rate and timing application, reaching $100 \%$ control at 50 days after application. Atrazine + simazine tre atments were no effective on johns on grass control mainly at late postemergence application with addition of mineral oil. Corn yield increased 44 and 34\%, respectively, on early and late postemergence applications of nicosulfuron. No com injury was observed for any herbicide treatments.

Key words: Sorghum halepense, sulfonylurea, postemergence control, application timing, triazines.

1Recebido para publicação em 02/08/96 e na forma revisada em 03/04/97.

2Eng. Agr., Dr., Pesquisad or Científico, Bolsista do CNPq, Seção de Fisiologia, Instituto Agronômico de Campinas, Caixa Postal, 28, CEP 13001-970, Campinas, SP. 


\section{INTRODUÇÃO}

Das espécies de plantas daninhas que infestam as culturas econômicas no mundo, cerca de $44 \%$ pertence à família das gramíneas, destacando-se entre elas o Sorghum halepense, que causa sérios prejuízos à agricultura em 51 países (Cobb, 1992).

O Sorghum halepense, conhecido no Brasil como capim-massambará, é uma gramínea perene que se propaga através de sementes e de rizomas, sendo que as plântulas originadas de sementes são capazes de produzir rizomas poucas semanas após a emergência (McWhorter, 1972).

A remoção da parte aérea, através de capinas mecânicas, é pouco eficiente no controle do capim-massambará pois não afeta as gemas dos rizomas que permanecem viáveis e capazes de reproduzir uma nova planta. Do mesmo modo, tratos culturais como aração e gradagem não controlam essa gramínea, pois fragmentam os rizomas, aumentando sua capacidade de reprodução (McWhorter, 1972). Por outro lado, a maioria dos herbicidas disponíveis só é eficiente no controle da parte aérea, mas tem pouco efeito sobre os rizomas, em virtude da baixa translocação para esses orgãos (Banks \& Tripp, 1983; Millhollon, 1985).

O capi m-mass ambará é uma planta daninha muito importante para a cultura do milho, pois reduz drasticamente a produção quando não controlado (Bendixen, 1986). Até recentemente não havia herbicidas disponíveis para o controle eficiente pré emergente, e seletivo pós emergente dos rizomas do capim massambará.

Com o aparecimento a partir dos anos 80, de uma nova classe de herbicidas de pósemergência pertencentes ao grupo das sulfoniluréias, abriram-se novas perspectivas para o controle do capim-massambará como gramínea infestante na cultura do milho. As sulfoniluréias, em cujo grupo está incluido o nicosulfuron, apresentam al ta seletividade e bloqueiam o crescimento das plantas daninhas atra vés da inibição da acetolactase sintase, a primeira enzima específica requerida para a biosíntese dos aminoácidos es se nciais valina, leucina e isoleucina (Ray, 1984; Chaleff \& Mauvais, 1984).

$\mathrm{O}$ alto grau de tecnificação alcançado na cultura do milho nas principais regiões produtoras do Brasil, tem levado a utilização de herbicidas de pós-emergência, alguns deles de elevado grau de seletividade à cultura, e de controle sobre ampla faixa de espécies infestantes de gramíneas e de plantas de folhas largas (Blanco et al. 1976; Almeida, 1991). Foy \& Witt (1990) verificaram em cultura de milho no estado de Virginia-EUA, que a aplicação de nicosulfuron em pósemergência apresentou alto nível de controle do capim-massambará (83 a $97 \%$ ), resultando em expresivos aumentos na produção. Entretanto, não há relatos de estudos sobre a infestação e controle de capim-massambará na cultura do milho em condições brasileiras.

O objetivo deste trabalho foi estudar a eficiência do herbicida nicosulfuron no controle do capim-massambará como infestante da cultura do milho.

\section{MATERIAL E MÉTODOS}

$\mathrm{O}$ experimento foi conduzido no município de Rio Claro, SP, em latossolo roxo, que apresentava como infestante principal o capim-massambará (Sorghum halepense) e secundariamente vegetação desprezível constituida principalmente de picão-preto (Bidens pilosa), capim-colchão (Digitaria sanguinalis), falsa-serralha (Emilia sonchifolia) e apaga-fogo (Alternan the ra fic oidea). Utilizou-se o mil ho híbrido Cargill-505, e a semeadura foi efetuada em 15 de dezembro de 1991.

O delineamento experimental utilizado foi o de blocos ao acaso, com doze tratamentos, repetidos seis vezes. As parcelas foram constituídas de três linhas de plantas de milho de $6 \mathrm{~m}$ de comprimento, espaçadas $1 \mathrm{~m}$ entre si, com densidade média de 10 plantas por metro linear. Foi considerada como útil, para a avaliação da produção, a linha central, desprezando-se $1 \mathrm{~m}$ em cada extremi dade. Para avaliação da infestação e do controle das plantas daninhas, utilizaram-se as 
áreas adjacentes à linha central (1m de cada lado), de sprezando-se, a ex emplo da aval iação da produção, $1 \mathrm{~m}$ de cada extremidade.

Os tratamentos consistiram de aplicações dos herbicidas nicosulfuron (SL-950 - SC 40g/l) e da mistura atrazine + simazine (Triamex $500 \mathrm{SC}$ ) que foram efetuadas em 5 e 12 de janeiro de 1992, considerad as, re spectivamente, como pós emergência inicial e pós emergência tardia. Na primeira, o nicosulfuron foi utilizado nas doses de $40,50,60$ e $80 \mathrm{~g} / \mathrm{ha}$ e a mis tura de triazinas na dose de $1500 \mathrm{~g} /$ ha de atrazine $+1500 \mathrm{~g} /$ ha de simazine, com e sem adição de óleo mineral na concentração de 3 litros por hectare. Nesta época, as plantas de milho se encontravam no estádio de desenvolvimento vegetativo correspondente a 4-6 folhas e as plantas de capim-massambará com 3-4 folhas.

$\mathrm{Na}$ aplicação de pós emergência tardia o nicosulfuron foi utilizado nas doses de 50, 60 e $80 \mathrm{~g} / \mathrm{ha}$ e a atrazine + simazine, com e sem a ad ição de óleo mineral, nas mesmas doses utilizadas na primeira época. Nesta aplicação, as plantas de milho estavam com 5-7 folhas, o capimmassambará e as demais plantas daninhas com 4-6 folhas.

A pulverização foi efetuada com um equipamento costal manual, munido de barra com dois bicos de jato plano (tipo leque) 80-02, com consumo de calda equivalente a 340 litros por hectare.

Os efeitos dos herbicidas, no controle do capim-massambará, nas duas épocas de aplicação, foram determinados simultaneamente aos 14, $34 \mathrm{e}$ 50 dias após a primeira aplicação (DAPA), avaliando-se visualmente o tamanho e número dos perfilhos em relação à testemunha não capinada, de acordo com uma escala de 0-100, em que os valores zero e 100 representam, respectivamente, o controle nulo e total das plantas daninhas. Imediatamente após a última avaliação visual (50 DAPA), coletou-se, ao acaso em cada parcela, os perfilhos de capim-massambará contidos numa área de $0,25 \mathrm{~m}^{2}$, determinando-se o número e a massa seca. Ao final do experimento, quando as espigas de milho estavam secas, avaliou-se a produção de grãos.

Os efeitos dos tratamentos foram analisados pelo teste $\mathrm{F}$ e as médias comparadas pelo teste de Tukey ao nível de 5\% de probabilidade. Na análise da variância, os dados de porcentagem de controle das plantas daninhas, em relação à testemunha, foram transformados em $\operatorname{arcsen} \sqrt{x}$.

\section{RESULTADOS E DISCUSSÃO}

As médias das porcentagens de controle do ca pi m-ma ss amba rá, na s três épocas de avaliação, são apresentadas na Tabela 1 . Na primeira avaliação, efetuada aos 14 dias após a primeira ap licação dos he rbicidas (D APA), observa-se que os tratamentos com nicosulfuron atingiram altos níveis de controle (acima de 90\%) em re lação aos tratamento s com atrazine + simazine, adicionados ou não de óleo mineral (55 a $72 \%$ de controle). Nesta avaliação, as plantas do capim-massambará, tratadas com nicosulfuron, apresentavam sintomas de fitotoxicidade, caracterizada por coloração arroxeada, semelhante a observada por Foy \& Witt (1990). O nicosulfuron foi eficiente no controle do capi mmassambará mesmo nas doses mais baixas, não havendo diferença significativa entre as várias concentrações utilizadas e épocas de aplicação. Tanto as aplicações em pós-emergência inicial (3 a 5 folhas) como tardia (4 a 6 folhas) apresentaram controle excelente (acima de 90\%), o que discorda das observações de Obrigawitch et al. (1990). Es se s autores ve rificaram que aplicações de nicosulfuron, quando o capim mass ambará apre sentava de 5 a 8 folhas, foram mais eficientes do que em estádios mais precoces (2 a 5 folhas), para todas as dos es utilizadas, sendo que a maior eficiência do tratamento de pós emergência tardia foi atribuída ao melhor controle da rebrota da parte aérea proveniente dos rizomas. Citam ai nda que não houve diferença no padrão de translocação do ${ }^{14} \mathrm{C}$ nicosulforon aplicado nas folhas para os rizomas, nos diferentes estádios de crescimento estudados. No presente trabalho, tanto as aplicações em

Planta Daninha, v. 15, n. 1, 1997. 
pós-emergência inicial como tardia apresentaram controle do capim-massambará, não havendo reinfe stação até o final do ciclo da cultura do milho.

TABELA 1. ficiência de nicosulfuron e atrazine + simazine , com ou sem a adição de óleo mineral no controle de capim -massamb ará (Sorghum halepense) na cultura do milho, Rio Claro, SP, 1991. Média de seis respetições, das avaliações visuais de controle.

\begin{tabular}{|c|c|c|c|c|c|c|c|}
\hline \multirow{3}{*}{ Tratamentos } & \multirow{3}{*}{$\begin{array}{l}\text { Doses } \\
\text { (g/ha) }\end{array}$} & \multicolumn{6}{|c|}{ Dias após a primeira aplicação (DAPA) } \\
\hline & & \multicolumn{2}{|c|}{14} & \multicolumn{2}{|c|}{34} & \multicolumn{2}{|c|}{$\mathbf{5 0}$} \\
\hline & & $\begin{array}{c}\% \\
\text { controle } \\
\end{array}$ & $\begin{array}{c}\text { Arc sen } \\
\sqrt{x} \\
\end{array}$ & $\begin{array}{c}\% \\
\text { controle } \\
\end{array}$ & $\begin{array}{l}\text { Arc sen } \\
\sqrt{x} \\
\end{array}$ & $\begin{array}{c}\% \\
\text { controle } \\
\end{array}$ & $\begin{array}{c}\text { Arc sen } \\
\sqrt{x} \\
\end{array}$ \\
\hline Nicosulfuron (Pós-inicial) & 40 & 94,5 & $76,49 \mathrm{~b}$ & 98,0 & $81,96 \mathrm{c}$ & 100,0 & - \\
\hline Nicosulfuron (Pós-inicial) & 50 & 94,2 & $76,08 \mathrm{~b}$ & 97,3 & $81,56 \mathrm{c}$ & 100,0 & $\cdot$ \\
\hline Nicosulfuron (Pós-inicial) & 60 & 93,1 & $74,80 \mathrm{~b}$ & 97,2 & $81,39 \mathrm{c}$ & 100,0 & - \\
\hline Nicosulfuron (Pós-inicial) & 80 & 92,6 & $74,20 \mathrm{~b}$ & 98,0 & $81,96 \mathrm{c}$ & 100,0 & - \\
\hline Nicosulfuron (Pós-tardia) & 50 & 92,4 & $73,95 \mathrm{~b}$ & 96,7 & $79,58 \mathrm{c}$ & 100,0 & - \\
\hline Nicosulfuron (Pós-tardia) & 60 & 93,1 & 74,72 b & 96,7 & $79,58 \mathrm{c}$ & 100,0 & - \\
\hline Nicosulfuron (Pós-tardia) & 80 & 93,5 & $75,21 \mathrm{~b}$ & 96,8 & $79,66 \mathrm{c}$ & 100,0 & - \\
\hline $\begin{array}{l}\text { Atrazine + simazine } \\
\text { (Pós-inicial) }\end{array}$ & $1500+1500$ & 72,2 & 58,19 a & 65,0 & $53,76 \mathrm{ab}$ & 72,8 & $58,57 \mathrm{~b}$ \\
\hline $\begin{array}{l}\text { Atrazine }+ \text { simazine } \\
\text { (Pós-tardia) }\end{array}$ & $1500+1500$ & 63,2 & 52,67 a & 68,8 & $56,02 \mathrm{~b}$ & 32,8 & 34,96 a \\
\hline $\begin{array}{l}\text { Atrazine }+ \text { simazine }+(\text { O.M. })^{1} \\
\text { (Pós-inicial) }\end{array}$ & $1500+1500$ & 63,5 & $52,83 \mathrm{a}$ & 63,6 & $52,89 \mathrm{ab}$ & 31,8 & $34,34 \mathrm{a}$ \\
\hline $\begin{array}{l}\text { Atrazine + simazine + (O.M.) } \\
\text { (Pós-tardia) }\end{array}$ & $1500+1500$ & 55,5 & 48,18 a & 51,5 & 45,86 a & 51,2 & 45,66 a \\
\hline $\begin{array}{l}\text { Testemunha sem capina } \\
\text { ( } \% \text { de cobertura do solo) }\end{array}$ & & 25 & - & 39 & - & 38 & - \\
\hline $\mathrm{F}$ & & & $22,68^{* *}$ & & $66,34^{* *}$ & & $16,01^{* *}$ \\
\hline $\mathrm{CV} \%$ & & & 8,74 & & 6,27 & & 16,06 \\
\hline
\end{tabular}

** Significativo ao nivel de $1 \%$ de probabilidade.

(1) O.M. Óleo mineral $(760 \mathrm{~g} / \mathrm{l})$ na dose de $3 \mathrm{t} / \mathrm{ha}$

Médias seguidas da mesma letra não diferem estatisticamente pelo teste de Tukey, ao nível de $5 \%$ de probabilidade.

Para análise de variância os dados de porcentagem foram transformados em arc sen $\sqrt{\chi}$.

Na avaliação efetuada aos 34 DAPA, o controle do ca pi m-mass abará já era quas e completo nos tratamentos com nicosulfuron, observando-se grande número de plantas mortas. Entretanto, os trat amen to s com atrazine + simazine foram pouco eficientes, apresentando um controle de apenas $65 \%$ em relação à testemunha.

Aos 50 DAPA, todos os tratamentos com nic osulfuron aprese ntaram $100 \%$ de controle, tanto para o capim-massambará, como para as demais espécies de plantas daninhas presentes na áre a experimental, superando os valores (83 a $97 \%$ ) obtidos por Foy \& Witt (1990). Dos tratamentos com atrazine + simazine, apenas a aplicação em pós-emergência inicial apresentou eficiência satisfatória $(72,8 \%)$, nos demais o nível de controle foi muito baix o, ou seja, menor que $51,2 \%$.

A Tabela 2 mostra a infestação de capimmassambará presente nos tratamentos com 
atrazine + simazine e na testemunha aos 50 DAPA, efetuada através de contagem do número e massa seca dos perfilhos. De modo geral, a densidade dos perfilhos, por unidade de área, pouco variou com as aplicações de atrazine + si mazi ne, en quan to que a mass a seca foi reduzida si gnifica ti va me nte em relação à testemunha, destacando-se o tratamento de pósemergência inicial sem adição de óleo mineral. Observou-se ta mbém que nas parcelas não tratadas a popu lação do capim-mass ambará era densa e vigorosa.

TABELA 2. Infes tação do capi m-massambará (Sorghum halepense) na cultu ra do milho e co ntrole aos $50 \mathrm{DAPA}^{2}$, através de pulverizações com atrazine + simazine com e sem adição de óleo mineral, Rio Claro, SP, 1991. Média de seis repetições.

\begin{tabular}{|c|c|c|c|c|}
\hline Tratamentos & $\begin{array}{l}\text { Doses } \\
\text { (g/ha) }\end{array}$ & $\begin{array}{l}N^{\circ} \text { de Perfilhos } \\
\left(n^{\circ} / m^{2}\right)\end{array}$ & $\begin{array}{c}\text { Peso de Massa } \\
\text { Seca de Perfilhos } \\
\left(\mathrm{g} / \mathrm{m}^{2}\right)\end{array}$ & $\begin{array}{c}\text { Relação Massa } \\
\text { Seca/Perfilhos } \\
\text { (g/perfilho) }\end{array}$ \\
\hline Atrazine + simazine (Pós-inicial) & $1500+1500$ & $72,33 \mathrm{ab}$ & $66,48 \mathrm{a}$ & $1,12 \mathrm{a}$ \\
\hline Atrazine + simazine (Pós-tardia) & $1500+1500$ & $78,67 \mathrm{~b}$ & $159,60 \mathrm{~b}$ & $2,44 \mathrm{~b}$ \\
\hline $\begin{array}{l}\text { Atrazine }+ \text { simazine }+(\mathrm{O} . \mathrm{M})^{(1)} \\
\text { (Pós-inicial) }\end{array}$ & $1500+1500$ & $74,67 \mathrm{ab}$ & $160,20 \mathrm{~b}$ & $2,58 \mathrm{~b}$ \\
\hline $\begin{array}{l}\text { Atrazine + simazine + (O.M) } \\
\text { (Pós-tardia) }\end{array}$ & $1500+1500$ & $60,33 \mathrm{a}$ & $144,20 \mathrm{~b}$ & $2,82 \mathrm{~b}$ \\
\hline Testemunha sem capina & & $66,33 \mathrm{ab}$ & $288,40 \mathrm{c}$ & $5,64 \mathrm{c}$ \\
\hline $\mathrm{F}$ & & $4,40^{*}$ & $64,31^{* *}$ & $45,64 * *$ \\
\hline $\mathrm{CV} \%$ & & 12,95 & 14,86 & 20,56 \\
\hline
\end{tabular}

* Significativo ao nivel de $5 \%$ de probabilidade.

** Significativo ao nivel de $1 \%$ de probabilidade.

O.M.- Óleo mineral $(760 \mathrm{~g} / \mathrm{l})$ na dose de $3 \mathrm{l} / \mathrm{ha}$.

${ }^{2}$ Dias após a primeira aplicaçằo.

Médias seguidas da mesma letra não diferem estatisticamente pelo teste de Tukey, ao nivel de $5 \%$ de probabilidade.

Observações efetuadas durante todo o ciclo vegetativo das plantas mostraram que os herbicidas não causara $\mathrm{m}$ fitotoxicidade à cultura do milho. Foy \& Witt (1990) também verificaram que a aplicação de nicosulfuron não provocou injúrias às plantas de milho. Tal fato mostra a seletividade do nicosulfuron que provavelmente é obtida pela rápida inativação metabólica do herbicida em espécies tolerantes (Foy \& Witt, 1990). Obrigawitch et al. (1990) mostraram que após 20 horas o milho metabolizou cerca de $90 \%$ do nicosulfuron absorvido pelas folhas, enquanto que no capim-massambará não houve metabolismo detectável.

O capim-massambará através de seus efeitos competitivos por luz, umidade e nutrientes mine rais pode reduzir consideravelmente a produção do milho (Bendixen, 1986). A Tabela 3 mostra que a ausência de competição, proporcionada pelos tratamentos com nicosulfuron em pós-emergência inicial e tardia ocasionou aumentos médios de 44 e 34\%, respectivamente, na produção do milho, em relação à testemunha. Dentre os tratamentos com atrazine + simazine, somente as aplicações efetuadas em pós-emergência inicial, sem a adição de óleo mineral, proporcionaram produções superiores à testemunha.

Os dados obtidos neste trabalho permitem as se gu in tes conclusões: o ni cosulfur on em aplicações de pós-emergência inicial e tardia foi eficiente no controle do capim-massambará; a

Planta Daninha, v. 15, n. 1, 1997. 
eficiência do nicosulfuron no controle do capimmassambará foi independente das doses e épocas de aplicação; as aplicações de atrazine + simazine não apresentaram controle satisfatório do capimmass ambará em pós-emer gência; a ação da at razine + simazine no controle do capim- massambará em pós-emergência ocorreu princi palmente na redução do crescimento dos perfilhos e aplicações de nicosulfuron em pós-emergência inicial e tardia, causaram aumentos na produção de milho.

TABELA 3. Efeito da aplicação dos herbicidas nicosulfuron e atrazine + simazine, adicionado ou não de óleo mineral na produção de milho, Rio Claro, SP, 1991. Médias de seis repetições.

\begin{tabular}{|c|c|c|c|}
\hline Tratamento & $\begin{array}{c}\text { Doses } \\
\text { g/ha }\end{array}$ & $\begin{array}{c}\text { Fitotoxicidade } \\
\text { DAPA }^{2} \\
14-50\end{array}$ & $\begin{array}{r}\text { Produção } \\
(\mathrm{kg} / \mathrm{ha})\end{array}$ \\
\hline Nicosulfuron (Pós-inicial) & 1,00 & 0 & $7692,6 \mathrm{e}$ \\
\hline Nicosulfuron (Pós-inicial) & 1,25 & 0 & $7666,6 \mathrm{e}$ \\
\hline Nicosulfuron (Pós-inicial) & 1,50 & 0 & 7328,3 de \\
\hline Nicosulfuron (Pós-inicial) & 2,00 & 0 & 6807,5 cde \\
\hline Nicosulfuron (Pós-tardia) & 1,25 & 0 & $7080,6 \mathrm{de}$ \\
\hline Nicosulfuron (Pós-tardia) & 1,50 & 0 & $6666,6 \mathrm{~cd}$ \\
\hline Nicosulfuron (Pós-tardia) & 2,00 & 0 & $6898,5 \mathrm{~cd}$ \\
\hline Atrazine + simazine (Pòs-inicial) & 6,00 & 0 & 6872,6 cde \\
\hline Atrazine + simazine (Pós-tardia) & 6,00 & 0 & $6078,5 \mathrm{bc}$ \\
\hline Atrazine + simazine + (O.M.) ${ }^{1}$ (Pós-inicial) & 6,00 & 0 & $5636,0 \mathrm{ab}$ \\
\hline Atrazine + simazine $+($ O.M) (Pós-tardia) & 6,00 & 0 & $6130,5 \mathrm{bc}$ \\
\hline Testemunha sem capina ( $\%$ de cobertura do solo) & - & & 5107,5 a \\
\hline $\mathrm{F}$ & & & $15,15^{* *}$ \\
\hline $\mathrm{CV} \%$ & & & 7,48 \\
\hline
\end{tabular}

\section{LITERATURA CITADA}

ALMEIDA, F. S. Controle de plantas daninhas em plantio direto. IAPAR: Londrina, 1991. 3p. (Circular Técnica).

B ANKS, P.A., TRIPP, T.N. Control of johnsongrass (Sorghum halepense) in soybeans with foliar-applied herbicides. Weed Sci., Champaign, v.31, n. 1, p.628633, 1983.

BENDIXEN, L.E. Corn (Zea mays) yield in relation to johnsongrass halepense) population. (Sorghum Champaign ,v.34, n.3, p.449-451, 1986. 
BLANCO, H.G., ARAÚJO, I.B.M., OLIVEIRA, D.A. Estudo sobre a competição de plantas daninhas na cultura do milho (Zea mays L.); determinação do período de competição. Arquivos do Instituto Biológico, São Paulo, v.43, n.3/4, p.105-114, 1976.

COBB, A. Herbicides and plant physiology. London: Chapman \& Hall, 1992. 175 p.

CHALEFF, R.S., MAUVAIS, C.J. Acetolactate synthase is the site of action of two sulfonylurea herbicides in higher plants.

Science, Washington, v.224, p.1443-1444, 1984.

FOY, C.L., WITT, H.L. Johnsongrass control with DPX-V9360 and CGA-136872 in corn (Zea mays) in Virginia. We ed Te ch nol., Champaign,v.4, n.3, p.615-619, 1990.
McWHORTER, C.G. Factors affecting johnsongrass rhizome production and germination. Weed Sci., Champaign, v.20, n.1, p.41-45, 1972.

MILL HOLL ON, R.W. Prog res si ve kill of rhizomatous johnsongras s (Sorghum halepense) with repeated treatment with dalapon, MSMA, or asulam. Weed Sci., Champaign, v.33, n.2, p.216-221, 1985.

OB RIGA WITCH, T. T., KEN YON, W.H., KURATLE, H. Effect of application timing on rhizome johnsongrass (Sorghum halepense) control with DPX-V9360. Weed Sci., Champaign, v.38, n.1, p.45-49, 1990.

RAY, T.B. Site of action of chlorsulfuron. Inhibition of valine and isoleucine biosynthesis in plants. Plant Physiology, Lancaster, v.75, n.2, p.827-831, 1984. 